\title{
The Solution of the Wheel Mechanism with Integrated Drive Unit
}

\author{
Oskar Ostertag ${ }^{1, *}$, Michal Fabian ${ }^{2}$ \\ ${ }^{1}$ Department of Applied Mechanics and Mechatronics, Faculty of Mechanical Engineering, Technical University of Košice, Košice, \\ Slovak Republic \\ ${ }^{2}$ Department of Machine Design, Transport and Logistics, Faculty of Mechanical Engineering, Technical University of Košice, \\ Slovak Republic \\ *Corresponding author: oskar.ostertag@tuke.sk
}

Received October 08, 2014; Revised October 14, 2014; Accepted November 03, 2014

\begin{abstract}
In this article, we deal with the conceptual model of wheel mechanism with integrated drive unit. This solution is expected to reduce the weight of the moveable mechanisms and to increase security during their operation. The aim is also to reduce their actual operation costs.
\end{abstract}

Keywords: car, wheel mechanism, strength calculation, system dynamics

Cite This Article: Oskar Ostertag, and Michal Fabian, "The Solution of the Wheel Mechanism with Integrated Drive Unit.” American Journal of Mechanical Engineering, vol. 2, no. 7 (2014): 244-246. doi: 10.12691/ajme-2-7-14.

\section{Introduction}

In this article, we deal with a wheel mechanism project with a directly integrated drive and control unit, shockabsorber and braking system. The premises, is to replace the conventional internal combustion engine with an electric motor on condition that this will be directly integrated in the driving wheel hubs. The system of independently operating electric motors enables the autonomy of all travelling device wheels and kinetic energy recovery at deceleration, and its utilisation for the view of the drive system of a car, motorcycle or other wheel moving mechanisms is being changed via the weight reduction related with the exclusion of the combustion engine and gearbox. Independent wheel acceleration control appears to be very convenient. Its aim is to increase vehicle stability in critical situations. The presumptions are significant cost cuts for the manufacturing and operation of devices using this system. The integrated drive and control unit in individual wheels provide support for the driver in critical driving situations. A drive unit (electric motor), electric expansion wedge brake, and active wheel suspension are parts of the classic wheel rim (Figure 1), and electronic control, replace traditional hydraulics [1].

\section{Conceptual Model of the Wheel Mechanism}

In the first stage, we focused on the conceptual system model. The second stage was formed by a preliminary disposition design, i.e. springs, shock-absorbers and other parts arranged in the wheel hub. Here, we focused our attention on the assessment of the spring strength and their arrangement at a static action (effect) of external load. In the third stage, we focused on the system dynamics. The presumption of the solution was the completion of a mathematical model of the oscillation of a mechanical system. We thought about the vertical oscillation of the system as a whole, therefore of the whole travelling device with four wheels, and also with the effect of shock-absorbing on the system. The solution was carried out in the MATLAB environment [2]. This solution required to create a mathematical model with the help of movement differential equations.

The complete view of the construction solution and the description of the axle model mechanism are depicted in Figure 1 . The body (see 1) is mounted rotationally in the wheel hub with an electric motor mounted to it (see 5). The trailing arm (see 4) serves to fix the mechanism to the axle. The shock-absorber (see 2) as well as the springs (see 3), is fitted between the body and the trailing arm.
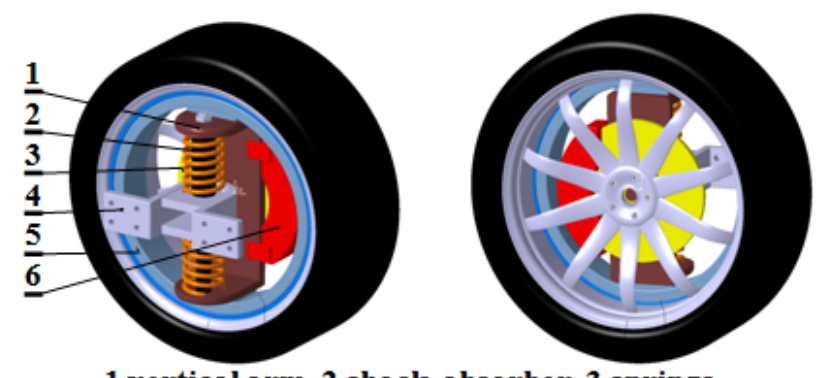

1 vertical arm, 2 shock-absorber, 3 springs, 4 horizontal arm, 5 electric drive, 6 brake

Figure 1. Construction solution of the axle mechanism

Construction solution of a tensile bed is possible due to diverse spring arrangements. In this solution, we can 
consider parallel, series, or combined springs arrangement (Table 1) [3]. Different combinations of this arrangement provide variability of solution, which can in addition be changed by the choice of different spring stiffness. In our case, we considered a series arrangement of springs. This solution brought us to a statically indefinite task. In this stage of the construction solution, we dealt only with the static action (effect) of strength impacts on the axle; we did not consider the fatigue strength of the springs, neither the oscillation of the system. When resolving the issue, we excluded absorption and focused only on one component of the axle, namely the spring.

Table 1. Spring arrangement

\begin{tabular}{|c|c|}
\hline Spring arragement & Stiffnes of the system \\
\hline 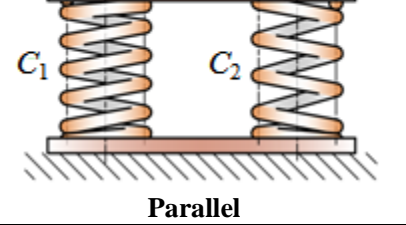 & $C=\sum_{i=1}^{2} C_{i}$ \\
\hline$F$ & $\frac{1}{C}=\sum_{i=1}^{2} \frac{1}{C_{i}}$ \\
\hline Combined & $\frac{1}{C}=\frac{1}{C_{1}}+\frac{1}{C_{2}+C_{3}}$ \\
\hline
\end{tabular}

\section{Springs Stiffness Control}

The spring arrangement represents a statically indefinite system [4]. Springs are inserted to the system with some pre-load, which is necessary to take into consideration when solving the issue. We also considered diverse stiffness of springs. The calculation was realized with the axle load of $F=3.3 \mathrm{kN}$, and the pre-load was concluded by the springs' compression to the value of $h-s=250 \mathrm{~mm}$, where $h$ is the spring strength, and $s$ is the trailing arm width. Calculation formulas derived for this case of pre-loaded springs and the resulting numeric data are in presented in Table 2. The solution was made in accordance with the regulations stated in [5].

Table 2. Calculation formulas and computed values

\begin{tabular}{|c|c|}
\hline Calculation formulas & Result \\
\hline $\begin{array}{l}\text { Resultant strength effect in spring } 1 \\
N_{1}=\frac{d^{4} G(2 L-h+s)}{64 n\left(R_{1}^{3}+R_{2}^{3}\right)}+\frac{F R_{2}^{3}}{R_{1}^{3}+R_{2}^{3}}\end{array}$ & $N_{1}=4.7 \mathrm{kN}$ \\
\hline $\begin{array}{l}\text { Resultant strength effect in spring } 2 \\
N_{2}=\frac{d^{4} G(2 L-h+s)}{64 n\left(R_{1}^{3}+R_{2}^{3}\right)}-\frac{F R_{1}^{3}}{R_{1}^{3}+R_{2}^{3}}\end{array}$ & $N_{2}=1.4 \mathrm{kN}$ \\
\hline $\begin{array}{l}\text { Resultant deformation of spring } 1 \\
y_{1}=\frac{R_{1}^{3}}{R_{1}^{3}+R_{2}^{3}}(2 L-h+s)+\frac{64 F R_{1}^{3} R_{2}^{3} n}{G d^{4}\left(R_{1}^{3}+R_{2}^{3}\right)}\end{array}$ & $y_{1}=50.1 \mathrm{~mm}$ \\
\hline $\begin{array}{l}\text { Resultant deformation of spring 2 } \\
y_{2}=\frac{R_{2}^{3}}{R_{1}^{3}+R_{2}^{3}}(2 L-h+s)-\frac{64 F R_{1}^{3} R_{2}^{3} n}{G d^{4}\left(R_{1}^{3}+R_{2}^{3}\right)}\end{array}$ & $y_{2}=19.9 \mathrm{~mm}$ \\
\hline $\begin{array}{l}\text { Shift of the body by effect of strength } F \\
\qquad y=\frac{64 F R_{1}^{3} R_{2}^{3} n}{G d^{4}\left(R_{1}^{3}+R_{2}^{3}\right)}\end{array}$ & $y=19.7 \mathrm{~mm}$ \\
\hline $\begin{array}{c}\text { Shear stress of spring } 1 \\
\tau_{1}=\frac{d G(2 L-h+s) R_{1}}{4 \pi n\left(R_{1}^{3}+R_{2}^{3}\right)}+\frac{16 F R_{1} R_{2}^{3}}{\pi d^{3}\left(R_{1}^{3}+R_{2}^{3}\right)}\end{array}$ & $\tau_{1}=601 \mathrm{MPa}$ \\
\hline $\begin{array}{c}\text { Shear stress of spring } 2 \\
\tau_{2}=\frac{d G(2 L-h+s) R_{2}}{4 \pi n\left(R_{1}^{3}+R_{2}^{3}\right)}-\frac{16 F R_{2} R_{1}^{3}}{\pi d^{3}\left(R_{1}^{3}+R_{2}^{3}\right)}\end{array}$ & $\tau_{2}=200 \mathrm{MPa}$ \\
\hline $\begin{array}{l}\text { Strength after the absolute unloading of spring } 2 \\
\qquad F_{0}=\frac{G d^{4}(2 L-h+s)}{64 R_{1}^{3} n}\end{array}$ & $F_{0}=6.6 \mathrm{kN}$ \\
\hline
\end{tabular}

Sizes of the springs were designed (proposed) according to preliminary strength calculations. The springs were chosen to be of cylindrical shape with a wire of a circular cross section. The technical characteristics of the springs, i.e. their construction design details and the characteristics of the springs' material can be seen in the attached Table 3 . We chose low alloy fine silicon-chrome-plated steel determined to refinement, as a springs material.

\begin{tabular}{|c|c|c|}
\hline Description & Spring 1 & Spring 2 \\
\hline Outer spring radius & $R_{e 1}=49 \mathrm{~mm}$ & $R_{e 2}=53 \mathrm{~mm}$ \\
\hline Medium spring radius & $R_{1}=43 \mathrm{~mm}$ & $R_{2}=47 \mathrm{~mm}$ \\
\hline Inner spring radius & $R_{i 1}=37 \mathrm{~mm}$ & $R_{i 2}=41 \mathrm{~mm}$ \\
\hline $\begin{array}{l}\text { Spring deformation in case of } \\
\text { full load }\end{array}$ & $y_{n 1}=76.9 \mathrm{~mm}$ & $y_{n 2}=97.9 \mathrm{~mm}$ \\
\hline Spring rigidity constant & $C_{1}=65 \mathrm{Nmm}^{-1}$ & $C_{2}=51 \mathrm{Nmm}^{-1}$ \\
\hline Active coil pitch & $t_{1}=38.9 \mathrm{~mm}$ & $t_{2}=391 \mathrm{~mm}$ \\
\hline \multicolumn{2}{|c|}{$\begin{array}{l}\text { Material identification of steel 54SiCr6 } \\
\text { (EN STN } 414260 \text { ). }\end{array}$} & \\
\hline \multicolumn{3}{|c|}{ Yield tensile strength of the wire material $R_{m}=1850 \mathrm{MPa}$. } \\
\hline \multicolumn{3}{|l|}{ Wire diameter $d=12 \mathrm{~mm}$. } \\
\hline \multicolumn{3}{|c|}{ Strength developed by the spring in case of full loading $F_{n}=5 \mathrm{kN}$. } \\
\hline \multicolumn{3}{|l|}{ Number of active coils $n=3.4$} \\
\hline \multicolumn{3}{|c|}{ Spring length in a free state $L=160 \mathrm{~mm}$. } \\
\hline
\end{tabular}




\section{Mathematical Model of the Oscillation of the Mechanical System of Chassis}

Calculation of kinematic values is demonstrated on a dual-mass dynamic model with additional shock-absorber and a spring (Figure 2). The model of the mechanical dual-mass system oscillation was solved in the MATLAB program environment. The solution required to put together movement equations of a free and loose mechanical system. Therefore, movement equations derived for the dual-mass model according to Figure 1, have the consequent form:

$$
\begin{aligned}
& m_{1} \ddot{x}_{1}+k_{1} x_{1}-2 k_{2}\left(x_{2}-x_{1}\right)-2 b_{2}\left(\dot{x}_{2}-\dot{x}_{1}\right)=0 \\
& m_{2} \ddot{x}_{2}+2 k_{2}\left(x_{2}-x_{1}\right)+2 b_{2}\left(\dot{x}_{2}-\dot{x}_{1}\right)=0,
\end{aligned}
$$

where spring stiffness is $k_{1}$ and tyre rigidity is $k_{2} ; b_{2}$ is absorption coefficient, and $m_{1}, m_{2}$ are mass weights of individual system constituents; $x_{i}, \dot{x}_{i}, \ddot{x}_{i}$ is a deviation of sprung mass from a balance positions, respectively its speed and acceleration.

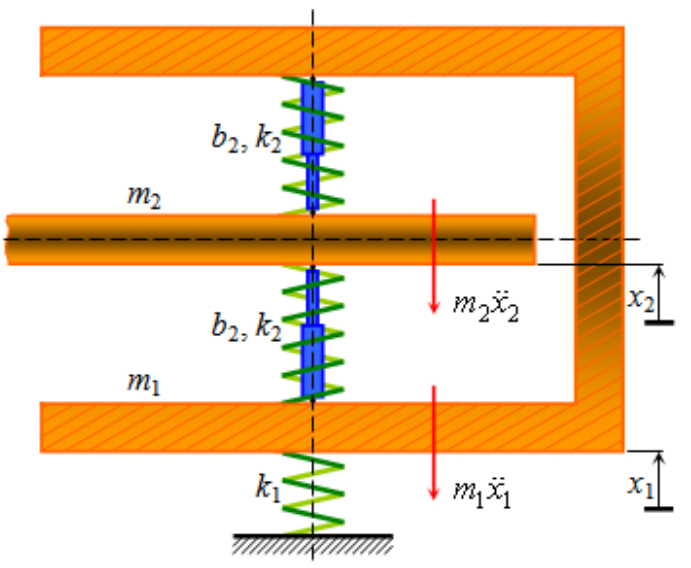

Figure 2. Passive quarter dual-mass model

The movement of a travelling device was simulated in accordance with the function defined by the equation:

$$
u(t)=\frac{A}{2}\left(1-\cos \left(2 \pi \frac{v t}{L_{0}}\right)\right),
$$

where $A, L_{0}$ is the height, respectively the obstacle length, and $v$ is the speed of the travelling mechanism. This equation describes a movement of a mass point on and over the obstacle in the form displayed in Figure 3.

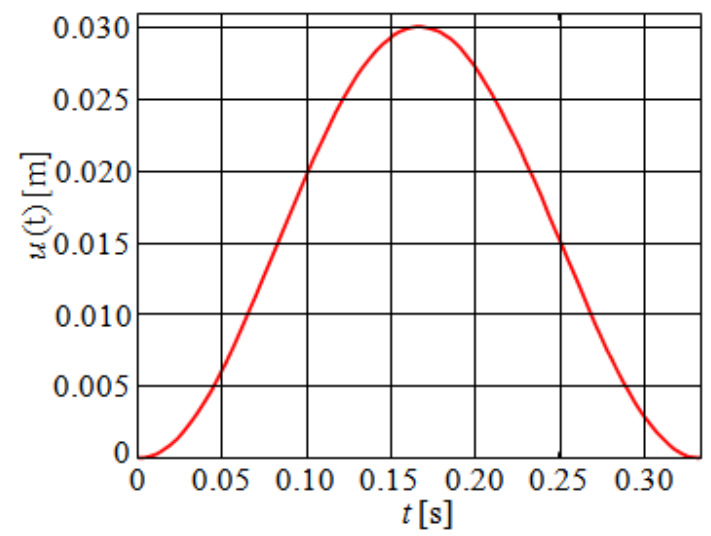

Figure 3. Obstacle form

\section{Results of the Oscilation Simulation of the Chassis Mechanical System}

The solution of the system of differential equations of second order (1) are the courses of speed and shift of masses $m_{1}, m_{2}$, creating the components of the solved chassis. We can observe these courses in Figure 4.

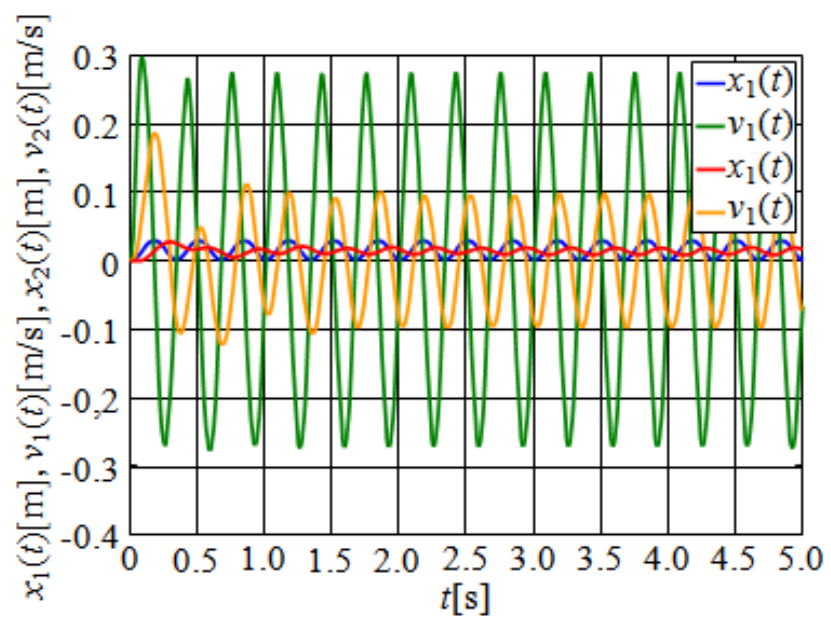

Figure 4. Dual-mass system speed and shift courses

\section{Conclusion}

Other possibilities of the change of the chassis stiffness are in choice of the arrangement of springs. We can also influence the final stiffness of the chassis by changing spring material. Within the further solution, we recommend to take into consideration:

- the fatigue strength of the springs,

- the speed, acceleration and inertial action (effects) of the chassis;

- the system oscillation,

- the stiffness of other system components, paying attention to other system components.

\section{Acknowledgement}

This task was resolved within the frame of the VEGA 1/0393/14 project.

\section{References}

[1] Moravič, M., Computer Modelling of the Suspension of the Running Gear (in Slovak). Diploma thesis, TU of Košice, Faculty of Mechanical Engineering 2013.

[2] Hroncová, D., The Solution of Mechanical Systems in the MATLAB, Simulink and SimMechanics Environments, The Dynamics of Rigid and Deformable Bodies 2008. Ústi nad Labem. p. 69-74.

[3] Trebuňa, F., Šimčák, F., The Resistance of Elements for Mechanical Systems (in Slovak) EMILENA Košice, 2004.

[4] Ostertag, O., Ostertagová, E., Sivák, P., The Assessment of Elastic Bearing of a Refrigeration Compressor (in Slovak), Transfer of Innovation, Vol. 16, 2010, p. 47-52.

[5] http://www.mitcalc.com/doc/sprigs/help/czspringstxt.htm. 